\title{
Lactobacillus plantarum CIDCA 8327: An $\alpha$-glucan producing-strain isolated from kefir grains
}

\author{
M.V. Gangoiti ${ }^{\mathrm{a}, \mathrm{b}}$, A.I. Puertas ${ }^{\mathrm{b}}$, M.F. Hamet $^{\mathrm{c}}$, P.J. Peruzzo ${ }^{\mathrm{d}}$, M.G. Llamas ${ }^{\mathrm{b}}$, M. Medrano ${ }^{\mathrm{c}}$, \\ A. Prieto ${ }^{\mathrm{e}}$, M.T. Dueñas ${ }^{\mathrm{b}}$, A.G. Abraham ${ }^{\mathrm{a}, \mathrm{c}, *}$ \\ a Área Bioquímica y Control de Alimentos, Dpto. Ciencias Biológicas, Facultad de Ciencias Exactas, Universidad Nacional de La Plata, 47 y 115, La Plata, \\ Buenos Aires, Argentina \\ b Dpto. de Química Aplicada, Facultad de Ciencias Químicas, Universidad del País Vasco (UPV/EHU), Paseo Manuel de Lardizabal 3, San Sebastián, País \\ Vasco, Spain \\ ' Centro de Investigación y Desarrollo en Criotecnología de Alimentos (CIDCA), Facultad de Ciencias Exactas, Universidad Nacional de La Plata - CONICET \\ CCT La Plata - CIC, 47 y 116, La Plata, Buenos Aires, Argentina \\ d Instituto de Investigaciones Fisicoquímicas Teóricas y Aplicadas (INIFTA), Facultad de Ciencias Exactas, Universidad Nacional de La Plata - CONICET CCT \\ La Plata, Diag. 113 y 64, La Plata, Buenos Aires, Argentina \\ e Departamento de Biología Medioambiental, Centro de Investigaciones Biológicas, Consejo Superior de Investigaciones Científicas, Ramiro de Maeztu 9, \\ Madrid, Spain
}

\section{A R T I C L E I N F O}

\section{Article history:}

Received 16 January 2017

Received in revised form 7 April 2017

Accepted 19 April 2017

Available online 23 April 2017

\section{Keywords:}

Lactobacillus plantarum

Kefir

Exopolysaccharides

Glucans

\begin{abstract}
A B S T R A C T
Lactobacillus plantarum CIDCA 8327 is an exopolysaccharide(EPS)-producer strain isolated from kefir with promising properties for the development of functional foods. The aim of the present study was to characterize the structure of the EPS synthesized by this strain grown in skim milk or semidefined medium (SDM). Additionally, genes involved in EPS synthesis were detected by PCR. L. plantarum produces an EPS with a molecular weight of $10^{4} \mathrm{Da}$ in both media. When grown in SDM produce an heteropolysaccharide composed mainly of glucose, glucosamine and rhamnose meanwhile the EPS produced in milk was composed exclusively of glucose indicating the influence of the sugar source. FTIR spectra of this EPS showed signals attributable to an $\alpha$-glucan. Both by ${ }^{1} \mathrm{H}$ NMR and methylation analysis it was possible to determine that this polysaccharide is a branched $\alpha-(1 \rightarrow 4)$-D-glucan composed of $80 \%$ linear $\alpha$-( $1 \rightarrow 4$ )-D-glucopyranosyl units and $19 \%(1 \rightarrow 4)$-D-glucopyranosyl units substituted at $O-3$ by single $\alpha$-D-glucopyranosil residues.
\end{abstract}

(c) 2017 Elsevier Ltd. All rights reserved.

\section{Introduction}

Among the "Food-Grade" biopolymers obtained from natural sources, exopolysaccharides (EPS) synthesized by lactic acid bacteria (LAB) have focused the attention of researchers and manufacturers since these EPS contribute to the rheology of the fermented product and -on account of EPS potential health promoting properties- may also contribute to the development of functional foods (Das, Baruah, \& Goyal, 2014; Patten \& Laws, 2015).

EPS produced by LAB present a wide range of compositions, structures, molecular masses and conformations depending on the

\footnotetext{
* Corresponding author at: Centro de Investigación y Desarrollo en Criotecnología de Alimentos (CIDCA), Facultad de Ciencias Exactas, Universidad Nacional de La Plata - CONICET CCT La Plata - CIC, 47 y 116, La Plata, Buenos Aires, Argentina.

E-mail addresses: analiaabraham@yahoo.com.ar, aga@biol.unlp.edu.ar (A.G. Abraham).
}

strain. The EPS can stay attached to the cell surface (capsular) or can be released to the culture media (Patten \& Laws, 2015). High molecular weight polysaccharides are widely used in the food industry as stabilizers, emulsifiers, and to improve texture and viscosity. The functionality of these polymers is originated from the structural differences in the sugar subunits, which is also the reason of the great diversity among bacterial EPS and novel EPS structures among LAB (Mozzi et al., 2006; Patten \& Laws, 2015). Complex genetic mechanisms of EPS production, carbohydrate source, incubation temperature and time, or $\mathrm{pH}$ of the culture medium were reported to affect in situ EPS production levels as well as their conformational characteristics, sugar linkages, and molecular mass (Ibarburu et al., 2015).

Many EPS synthesized by LAB have demonstrated to elicit some biological effect (Patten \& Laws, 2015). It has been reported that some EPS can have immunomodulatory (Hidalgo-Cantabrana et al., 2012; Medrano, Racedo, Rolny, Abraham, \& Pérez, 2011; Notararigo et al., 2014) and antitumoral activity in vivo (Wang et al., 2014), as 
well as an antagonistic effect against some intestinal pathogens in vitro (Medrano, Hamet, Abraham, \& Pérez, 2009; Živković et al., 2016), among other health benefits. Aditionally, the prebiotic effect of several EPS of LAB has been demonstrated in vitro (Korakli, Gänzle, \& Vogel, 2002) and in vivo (Hamet, Medrano, Pérez, \& Abraham, 2016).

Lactobacillus plantarum is a versatile microorganism that can be found in a wide range of habitats such as dairy, meat, and many plant fermentations, and it can reach high cell densities which are desirable for industrial applications. Different L. plantarum strains are able to produce heteropolysaccharides after grown in glucose or lactose (Dilna et al., 2015; Tallon, Bressollier, \& Urdaci, 2003; Wang et al., 2010; Zhang et al., 2013; Zhang, Liu, Tao, \& Wei, 2016) or homopolysaccharides: galactanes when lactose is the unique sugar source (Wang et al., 2014) or glucans when sucrose is the sugar source (Das \& Goyal, 2013).

Among the health benefits of EPS produced by some strains of L. plantarum it can be mentioned antioxidant activity (Zhang et al., 2013), antagonic activity against Bacillus cereus enterotoxin (Zhang et al., 2016), and antitumoral activity (Wang et al., 2014).

Kefir is a traditional beverage obtained by fermentation of milk with kefir grains that contain a wide diversity of lactic and acetic acid bacteria and yeasts immersed in a matrix composed of protein and the polysaccharide kefiran (Garrote, Abraham, \& De Antoni, 2001). Kefiran production was associated to Lactobacillus kefiranofaciens though another lactobacilli isolated from kefir were described to produce EPS after growth in milk (Hamet, Piermaria, \& Abraham, 2015; Wang, Zhao, Tian, Yang, \& Yang, 2015).

L. plantarum CIDCA 8327 is a facultative heterofermentative Lactobacillus isolated from kefir grains (Garrote et al., 2001). This strain presents a hydrophilic surface and a moderate adhesion to intestinal cells (Caco-2 cell line), while it had a strong inhibitory activity against Salmonella typhimurium, S. enterica, S. gallinarum, S. sonnei and Escherichia coli (Golowczyc et al., 2008). Besides, it is able to grow in the presence of bile salts and survives after one hour of exposure to pH 2.5 (Golowczyc et al., 2008). Moreover, some studies demonstrate that this strain is able to produce organic acids such as lactic and acetic acid, and substances of low molecular weight with antifungal properties after growth in whey media (Londero et al., 2011). In addition this strain is able to grow in milk and produces in situ an EPS of low molecular mass (Hamet et al., 2015).

The above mentioned characteristics, that turn $L$. plantarum CIDCA 8327 into a promising starter to be potentially included in functional foods, prompted us to study the production and chemical composition of the EPS synthesized in situ by this strain.

\section{Materials and methods}

\subsection{Strains and growth conditions}

L. plantarum CIDCA 8327 isolated originally from kefir grains (Garrote et al., 2001) was stored at $-80^{\circ} \mathrm{C}$ in sterile skim milk and reactivated in MRS broth at $30^{\circ} \mathrm{C}$ for $24 \mathrm{~h}$ (De Man, Rogosa, \& Sharpe, 1960). After that, L. plantarum was grown in UHT skim milk (Composition g/L: Protein 32, Fat 15, lactose 47; ashes 6.). La Serenisima, General Rodriguez, Argentina or in a semidefined medium (SDM) (Marieta, Ibarburu, Dueñas, \& Irastorza, 2009) for $21 \mathrm{~h}$ or $96 \mathrm{~h}$, depending on the determination. The SDM had the following composition: glucose $20 \mathrm{~g} / \mathrm{L}$, Casamino Acids (Becton Dickinson, Spain) $5 \mathrm{~g} / \mathrm{L}$, Difco ${ }^{\mathrm{TM}}$ Yeast Nitrogen Base (DYNB, Becton Dickinson, Spain) $6.7 \mathrm{~g} / \mathrm{L}, \mathrm{MnSO}_{4} \cdot \mathrm{H}_{2} \mathrm{O} 0.05 \mathrm{~g} / \mathrm{L}, \mathrm{K}_{2} \mathrm{HPO}_{4} 2 \mathrm{~g} / \mathrm{L}, \mathrm{NaAcO}$ $5 \mathrm{~g} / \mathrm{L}$, adenine $0.005 \mathrm{~g} / \mathrm{L}$, guanine $0.005 \mathrm{~g} / \mathrm{L}$, xanthine $0.005 \mathrm{~g} / \mathrm{L}$, uracil $0.005 \mathrm{~g} / \mathrm{L}$, and L-malic acid $4 \mathrm{~g} / \mathrm{L}$ pH 5.0.

\subsection{Transmission electron microscopy}

Analysis of the bacteria and the EPS by transmission electron microscopy (TEM) (Tecnai G2 Twin) was performed using samples prepared as follows. Glow-discharged carbon-coated grids were placed facedown over a droplet of each culture concentrated fivefold in $0.1 \mathrm{M} \mathrm{AcNH}_{4}, \mathrm{pH} 7$. After $1 \mathrm{~min}$, each grid was removed, blotted briefly with filter paper, and without being dried, negatively stained with $2 \%$ uranyl acetate for 30 s and then blotted quickly and air dried.

\subsection{DNA extraction and detection of genes}

Genomic DNA was prepared from late-logarithmic phase $L$. plantarum CIDCA 8327 cells using the DNeasy Blood \& Tissue Kit (Qiagen GmbH, Hilden, Germany) according to the manufacturer's instructions, except that we preincubated the cells with $2 \mathrm{U} / \mu \mathrm{L}$ mutanolysin (Sigma-Aldrich), and adjusted to a final DNA concentration of $40 \mathrm{ng} / \mu \mathrm{L}$ with water-free DNase and RNase.

For detection of polymerase genes in $L$. plantarum CIDCA 8327 associated with polysaccharide production, PCR primers were designed based on the predicted polymerase-cps genes sequences of $L$. plantarum WCFS1 available in the GenBank database (AL935263; Lp_1185, Lp_1204, Lp_1222, Lp_2101)(Table 1). Internal primers were also used to determine the sequence of both strands of genes. Primers were designed using the Primer V0.4.0 software (http://prodo.wi.mit.edu/primer3/). PCR reactions were carried out with Phusion High-Fidelity DNA Polymerase (Thermo Scientific, 163 Schwerte, Germany). Two annealing temperatures were used: $49^{\circ} \mathrm{C}$ for $c p s 1 \mathrm{I}, \mathrm{cps} 2 \mathrm{H}$ and $c p s 4 \mathrm{H}$, and $53^{\circ} \mathrm{C}$ for $c p s 3 \mathrm{~F}$. The PCR products were subjected to electrophoresis using a $1 \%(\mathrm{w} / \mathrm{v})$ agarose gel. The amplicons were purified using NucleoSpin ${ }^{\circledR}$ Gel and PCR Clean-up kit (Macherey-Nagel, GmbH \& Co., KG Düren, Germany), according to the manufacturerís instructions. Sequencing of the amplicons was carried out by Secugen S.L. (Madrid, Spain). The resulting sequences were analyzed by using the BLAST tool of the GenBank DNA database (http://www.ncbi.nlm.nih.gov/).

\subsection{EPSs isolation and purification}

The EPSs were isolated and purified from SDM or milk inoculated with $L$. plantarum CIDCA 8327. For the EPS produced in SDM, $L$. plantarum was cultured for $21 \mathrm{~h}$ or $96 \mathrm{~h}$ at $30^{\circ} \mathrm{C}$. After that, cells were removed by centrifugation for $30 \mathrm{~min}$ at $12,000 \mathrm{xg}$. The clear supernatant was collected, and the EPS was precipitated by adding 3 volumes of cold ethanol, followed by storage overnight at $-20^{\circ} \mathrm{C}$. The precipitate was recovered by centrifugation at $12,000 \times \mathrm{g}$ for $20 \mathrm{~min}$ at $4{ }^{\circ} \mathrm{C}$, dissolved in hot distilled water and dialyzed against deionized water, using a membrane (Medicell International Ltd., London, UK) having a cut-off of $3.5 \mathrm{kDa}$, for 2-3 days (water changed twice daily). Then, the retentate was lyophilized.

In the case of the EPS produced in milk, L. plantarum was incubated for $96 \mathrm{~h}$ at $30^{\circ} \mathrm{C}$. A volume of $1000 \mathrm{~mL}$ of fermented milk was treated in boiling water for $30 \mathrm{~min}$ with discontinuous stirring. The mixture was centrifuged at $10,000 \times \mathrm{g}$ for $20 \mathrm{~min}$ at $20^{\circ} \mathrm{C}$ (Avanti J25 Beckman Coulter Inc. centrifuge, Palo Alto, California). The polysaccharide in the supernatant was precipitated by addition of two volumes of cold ethanol and left at $-20^{\circ} \mathrm{C}$ overnight. The mixture was centrifuged at $10,000 \times \mathrm{g}$ for $20 \mathrm{~min}$ at $4{ }^{\circ} \mathrm{C}$. Pellets were dissolved in hot distilled water and dialyzed using a membrane (Spectra/Por, The Spectrum Companies, Gardena, CA, USA) having a cut-off of $1000 \mathrm{Da}$ for $48 \mathrm{~h}$ at $4{ }^{\circ} \mathrm{C}$ against four changes of twice-distilled water (Rimada \& Abraham, 2003). 
Table 1

Primers designed in this work to screen for CPS genes.

\begin{tabular}{|c|c|c|c|}
\hline Gene name & Locus_tag & Primer sequences $\left(5^{\prime} \rightarrow 3^{\prime}\right)$ & Expected fragment size (bp) \\
\hline \multirow[t]{3}{*}{ cps1I } & Lp_1185 & F: GGAATTTTACATGCCCGTTG & 1431 \\
\hline & & R: ACATGAGCGTTGAAAGTGGA & \\
\hline & & I: TTATGCTCAGAACGATACTTCTTGT & \\
\hline \multirow[t]{3}{*}{$\operatorname{cps} 2 \mathrm{H}$} & Lp_1204 & F: AATACTGGTAAGCATAAGATGATTTG & 1415 \\
\hline & & R:CAAATACTATTCGCAATATAAAACTCA & \\
\hline & & I: TTGGAAACTCAAATGGCCTC & \\
\hline $\operatorname{cps} 3 E$ & Lp_1221 & F: GCGTGAGACGAACGTGATT & 1148 \\
\hline \multirow[t]{2}{*}{$c p s 3 F$} & Lp_1222 & R: CCGCGTACGTTGATACAAAA & \\
\hline & & I: TGTGTGCGGCGTATTTGTAT & \\
\hline cps4I & Lp_2100 & F: GCCTGGTTTATGCGAGTGAT & 1531 \\
\hline \multirow[t]{2}{*}{ cps $4 H$} & Lp_2101 & R: ACTCCCTCGGCAAATAGGTT & \\
\hline & & I: TTGACCTGGATGCTATGGAT & \\
\hline
\end{tabular}

F: forward, R: reverse and I: intermediate primer.

The samples were tested for the absence of other sugars by qualitative thin layer chromatography (TLC) and of proteins the Bradford method according to Rimada and Abraham (2003).

\subsection{Exopolysaccharides quantification and molecular mass determination}

EPS produced in milk or SDM was quantified by the anthrone method (Hamet et al., 2015). The molecular weight of the EPS obtained were determined by high-performance size exclusion chromatography (HPLC-SEC, Agilent 1100 Series System, HewlettPackard, Germany) associated to a refractive index (RI) detection system, as described by Ibarburu et al. (2015), using as molecular mass dextran standards of molecular weight range from $10^{3}$ to $2 \times 10^{6} \mathrm{Da}$ (Sigma-Aldrich).

\subsection{Sugar composition}

The sugar composition of the EPSs was determined by a method described by Notararigo et al. (2013) after hydrolysis of the polysaccharides with $3 \mathrm{M}$ trifluoroacetic acid (TFA) at $121^{\circ} \mathrm{C}$ for $1 \mathrm{~h}$. The hydrolysed monosaccharides were converted into their corresponding alditol acetates, and analyzed and quantified by gas chromatography (GC 6890A, Agilent, Palo Alto, California, USA).

\subsection{Fourier-transform infrared (FTIR) spectroscopy}

Fourier-transformed Infrared Spectroscopy (FTIR) studies were performed using a Nicolet 380 instrument (Thermo Fisher Scientific) with a ZnSe single reflection ATR in the range $4000-650 \mathrm{~cm}^{-1}$. The number of scans per experiment was 64 , with a resolution of $4 \mathrm{~cm}^{-1}$.

\subsection{Methylation analysis}

The EPS obtained after grown in milk was methylated according to the method described by Ciucanu and Kerek (1984). The permethylated polysaccharide was hydrolyzed with $3 \mathrm{M}$ TFA at $121^{\circ} \mathrm{C}$ for $1 \mathrm{~h}$.

After hydrolysis, the partially methylated monosaccharides were reduced with deuterated $\mathrm{NaBH}_{4}$ and converted into their corresponding alditol acetates with $500 \mu \mathrm{L}$ of pyridine:acetic anhydride $(1: 1)$ for $1 \mathrm{~h}$ at $100^{\circ} \mathrm{C}$, as described by Laine, Sweeley, Li, Kisic, and Rapport (1972). Gas chromatography-mass spectrometry GC-MS analysis was carried out in a 6890A/5975C instrument from Agilent (Palo Alto, California, USA), with He as the carrier gas. The injector was programmed at $250^{\circ} \mathrm{C}$. Samples $(1 \mu \mathrm{L})$ were injected with a split ratio of $1: 50$ and their components separated in a HP5MS (Agilent) fused silica column $(30 \mathrm{~m} \times 0.25 \mathrm{~mm}$ I.D. $\times 0.2 \mu \mathrm{m}$ film thickness), with a temperature program starting at $160{ }^{\circ} \mathrm{C}(1 \mathrm{~min})$ and then rising $2{ }^{\circ} \mathrm{Cmin}^{-1}$ up to $200^{\circ} \mathrm{C}$. An $\mathrm{m} / z$ range between 40 and $450 \mathrm{amu}$ was scanned. Identification was done on the basis of the retention time and mass spectra of the compounds. Quantification was performed according to peak area (Ibarburu et al., 2015).

\subsection{NMR analysis}

Purified EPS were deuterium exchanged several times by freeze drying from $\mathrm{D}_{2} \mathrm{O}$ and then examined as solutions $(3 \mathrm{mg} / \mathrm{mL})$ in 99.98\% $\mathrm{D}_{2} \mathrm{O}$. Spectra were recorded at $60^{\circ} \mathrm{C}$ on a Bruker AMX500 spectrometer operating at $500.13 \mathrm{MHz}\left({ }^{1} \mathrm{H}\right.$-nuclear magnetic resonance). Chemical shifts were given in parts per million (Ibarburu et al., 2015).

\section{Results}

\subsection{L. plantarum CIDCA 8327 contains polysaccharide} polymerase genes associated with surface/exopolysaccharide production

L. plantarum strains that produce EPS contain several gene clusters involved in the synthesis of the biopolymer (Remus et al., 2012). To detect the presence of polysaccharide polymerase genes in the EPS-producing L. plantarum CIDCA 8327 strain, several cps primers were designed based on the L. plantarum WCFS1 complete genome sequence (GenBank accession number AL93526) (Table 1). In this strain 4 gene clusters (designated cps1, cps2, cps3 and cps4) independently contribute to the overall surface-associated polysaccharide. DNA of $L$. plantarum CIDCA 8327 yielded an 1148 bp PCR product with the $c p s 3 E-F$ primers, covering the $3^{\prime}$-end of $c p s 3 E$ gene and the $c p s 3 F$ gene. No PCR products were obtained with any of the other primers used. Comparison with nucleotide sequences in the database revealed that the sequenced fragment showed $98 \%$ identity with the $c p s 3 E-F$ region encoding putative polysaccharide biosynthesis proteins in L. plantarum WCFS1, ST-III, and ZJ316 strains (Accession Numbers: AL935263.2, CP002222.1, CP004082, respectively). In addition, TEM analysis of $L$. plantarum CIDCA 8327 grown in a semidefined medium (SDM) revealed the presence of extracellular material loosely attached to the bacterial surface (Fig. 1).

\subsection{The EPS produced by L. plantarum CIDCA 8327 depends on the growth medium}

EPS production was first quantified in SDM. Two time points of fermentation were sampled, $21 \mathrm{~h}$ (EPS 1 ) and $96 \mathrm{~h}$ (EPS 2), obtaining $40 \mathrm{mg} / \mathrm{L}$ and $120 \mathrm{mg} / \mathrm{L}$, respectively (Table 2). Both samples lacked protein based on the negative responses for Bradford test and absorption at $260 \mathrm{~nm} / 280 \mathrm{~nm}$ spectra (data not shown). Differ- 
Table 2

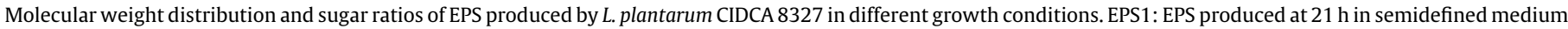
(SDM); EPS2: EPS produced at $96 \mathrm{~h}$ in SDM; and EPS3: EPS produced after $96 \mathrm{~h}$ in milk.

\begin{tabular}{|c|c|c|c|c|c|c|c|c|c|c|c|}
\hline \multirow[t]{2}{*}{ EPS } & \multirow[t]{2}{*}{ Medium } & \multirow[t]{2}{*}{ Hours of culture } & \multirow[t]{2}{*}{$\mathrm{pH}$} & \multirow[t]{2}{*}{ Total EPS $\left(\mathrm{mg} / \mathrm{L}^{-1}\right)$} & \multicolumn{3}{|c|}{ Molecular weight distribution (\%) } & \multicolumn{4}{|c|}{ Monosaccharide ratio } \\
\hline & & & & & $10^{5} \mathrm{Da}$ & $10^{4} \mathrm{Da}$ & $\overline{10^{3} \mathrm{Da}}$ & $\overline{\text { Glc }}$ & Gal & GlcN & $\overline{\text { Rha }}$ \\
\hline 1 & SDM & 21 & 3.9 & 40 & - & 61.2 & 38,8 & 10 & 0.6 & 6.6 & 2.7 \\
\hline 2 & SDM & 96 & 3.6 & 120 & 5.9 & 87.4 & 6.6 & 10 & 0.5 & 7 & 1.4 \\
\hline 3 & milk & 96 & 4.2 & 160 & & 100 & - & 10 & - & - & - \\
\hline
\end{tabular}

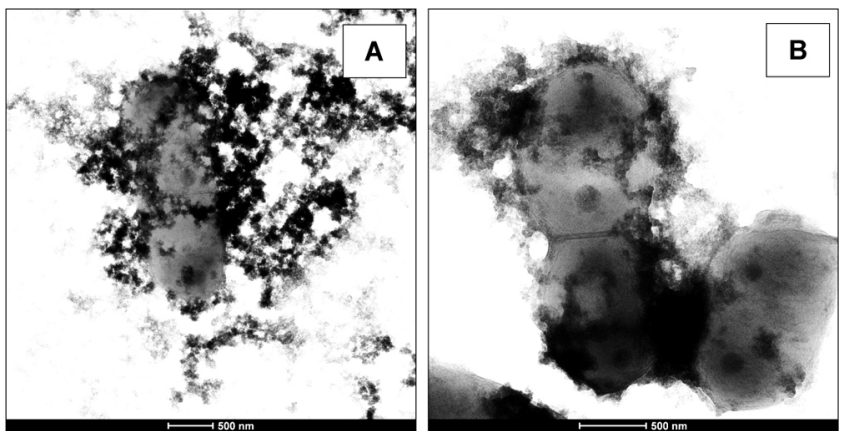

Fig. 1. Micrographs of $L$. plantarum CIDCA 8327 and its EPS obtained by Transmission Electron Microscopy. (A) Negative staining with uranyl acetate of whole cells of $L$. plantarum surrounded of exopolysaccharide (x 9600). (B) Detail of the cells and EPS (x 14,500).

ent patterns of molecular weight distribution were observed for the EPS recovered at the two times of fermentation (Table 2). While in EPS 1 there were $61.2 \%$ of the $10^{4} \mathrm{Da}$ and $38.7 \%$ of the $10^{3} \mathrm{Da}$ fraction, in EPS 2 most glucidic material $(87.4 \%)$ appears as a $10^{4} \mathrm{Da}$ fraction accompanied to two minor fractions of $10^{5} \mathrm{Da}$ and $10^{3} \mathrm{Da}$, indicating that incubation for longer period enables oligosaccharides polymerization.

With these data in mind, sterile skim milk was inoculated with L. plantarum CIDCA 8327 and after $96 \mathrm{~h}$ of fermentation $160 \mathrm{mg} / \mathrm{L}$ of an EPS (EPS 3) with a molecular mass of $10^{4}$ Da was obtained (Table 1). Sugar composition of the three EPS obtained was analyzed by HPAEC-PAD and it is presented in Table 2. The EPS 1 and EPS 2 produced in SDM were composed mainly of glucose, rhamnose and glucosamine (Table 2). Galactose was also detected in both EPS at lower percentage. Moreover, trace amounts of galacturonic acid were detected. On the other hand the EPS 3, produced in milk, was composed exclusively of glucose (Table 2) indicating that the sugar source influences the composition of the EPS produced by this strain.

The FTIR spectra of the three EPS are presented in Fig. 2. They show the typical signals of polysaccharides documented in literature, such as a broad band around $3260 \mathrm{~cm}^{-1}$ and a band at $2933 \mathrm{~cm}^{-1}$, arising from $\mathrm{O}-\mathrm{H}$ stretching and $\mathrm{C}-\mathrm{H}$ stretching, respectively, and a broad band located at $1000-1200 \mathrm{~cm}^{-1}$ assigned to overlapped $\mathrm{C}-\mathrm{O}, \mathrm{C}-\mathrm{C}$ stretching and $\mathrm{C}-\mathrm{OH}$ bending modes (Bremer \& Geesey, 1991; Howe, Ishida, \& Clark, 2002; Nataraj, Schomacker, Kraume, Mishra, \& Drews, 2008). The spectra of EPS 1 and EPS 2 showed also two peaks around $1540 \mathrm{~cm}^{-1}$ and $1639 \mathrm{~cm}^{-1}$, corresponding to $\mathrm{C}-\mathrm{N}$ and $\mathrm{C}=\mathrm{O}$ stretching, that are related to the amide linkage of aminosugars in the polysaccharides structure and a band at $1747 \mathrm{~cm}^{-1}$ typical of uronic acids (Kovács, Nyerges, \& Izvekov, 2008). These findings confirm the results from monosaccharide analysis. Absorptions in the "anomeric region" $\left(950-750 \mathrm{~cm}^{-1}\right)$ contain weak bands that inform on the anomeric configuration of the monosaccharides (Synytsya \& Novak, 2014). For these samples, the spectra presented a characteristic band located at $835 \mathrm{~cm}^{-1}$ from the $\alpha$-anomer of the glucose pyranoid ring as well as a signal at $873 \mathrm{~cm}^{-1}$ from galactose units (Kačuráková, Capek, Sasinkova, Wellner, \& Ebringerova, 2000).
Table 3

Results from the methylation analysis of the $\alpha$-glucan produced by L. plantarum CIDCA 8327 in milk.

\begin{tabular}{lll}
\hline Position of the O-methyl groups & Deduced linkages & $\%$ \\
\hline 1,5-diacetyl-2,3,4,6-tetramethyl-Glcp & Terminal (non-reducing end) & 4.7 \\
1,4,5-triacetyl-2,3,6-trimethyl-Glcp & $1 \rightarrow 4$ & 81.5 \\
1,3,4,5-tetracetyl-2,6-dimethyl-Glcp & $1 \rightarrow 3,4$ & 13.8 \\
\hline
\end{tabular}

On the other hand, all the vibrational peaks of the EPS 3 sample were similar to those obtained for $\alpha$-glucans. The bands at 1155 , $1022,930,850$ and $760 \mathrm{~cm}^{-1}$ evidenced the presence of a polysaccharide with $\alpha$ - linkages in the structure of this EPS (Kačuráková et al., 2000; Synytsya \& Novak, 2014). The absence of a band at $1745 \mathrm{~cm}^{-1}$ indicates that there are no carboxylic sugars in this EPS. In addition, there is no band around $1650 \mathrm{~cm}^{-1}$, confirming that the sample does not contain amino sugars. These observations are in agreement with the sugar compositional analysis.

\subsection{L. plantarum CIDCA 8327 produces an $\alpha$-glucan during fermentation of milk}

Since L. plantarum CIDCA 8327 was isolated from kefir and the research was focused on the use of this strain as milk starter, further studies were performed in order to elucidate the structure of the EPS produced by this strain during milk fermentation (EPS 3 ). Sugar linkages were determined and quantified upon analyzing by gas-liquid chromatography (GLC) the partially methylated alditol acetates (PMAAs) obtained from the sample (Table 3 ).

Methylation analysis showed the presence of 2,3,4,6-tetra-Omethyl glucitol corresponding to the non-reducing ends in the EPS chain, 2,3,6-tri-O-methyl glucitol indicating linear 1,4 glucosidic linkages, and 2,6-di-O-methyl glucitol resultant from branching points in glucose units attached through their positions 1,4 , and 3.

The ${ }^{1} \mathrm{H}$ NMR spectrum of the EPS 3 (Fig. 3) showed resonances of hydrogen corresponding to the glucosyl residue. The ${ }^{1} \mathrm{H}$ NMR spectrum of a polysaccharide can generally be divided into two major regions: the anomeric region $(\delta=4.3-5.5 \mathrm{ppm})$, and the ring proton region $(\delta=3.2-4.3 \mathrm{ppm})$.

As shown in Fig. 3, signals in the region between 5.3 and 4.5 ppm related to H1-4 and H1-3 are well resolved and indicate $\alpha$-Dglucans (Synytsya \& Novak, 2014). The main signals in the anomeric region correspond to protons bound to $C 1$ in the primary $\alpha 1 \rightarrow 4$ glycosidic bond ( $\delta=5.36 \mathrm{ppm})$, and $\mathrm{C} 1$ in the branching $\alpha 1 \rightarrow 3$ $(\delta=5.32 \mathrm{ppm})$, and a small signal at $\delta=4.95 \mathrm{ppm}$, attributable to $\alpha 1 \rightarrow 6$ glycosidic bonds was also observed (Cheng \& Neiss, 2012; Zang, Howseman, \& Shulman, 1991; Zang, Rothman, \& Shulman, 1990). The signals obtained in the spectrum in the ring proton region were poorly resolved due to the overlapping chemical shifts. However, it is possible to observe clearly the $\mathrm{H} 4^{\prime}$ peak corresponding to the protons bound to the free $\mathrm{C} 4$ non reducing ends $(\delta=3.41 \mathrm{ppm})$ and other intense peaks from the $\mathrm{H} 2(\delta=3.63 \mathrm{ppm})$, $\mathrm{H} 3(\delta=3.95 \mathrm{ppm}), \mathrm{H} 4(\delta=3.62 \mathrm{ppm}), \mathrm{H} 5(\delta=3.81 \mathrm{ppm})$ and H6a and H6b ( $\delta=3.86$ and $3.79 \mathrm{ppm}$, respectively) (Cheng \& Neiss, 2012; Nilsson, Bergquist, Nilsson, \& Gorton, 1996; Zang et al., 1990, 1991), but better assignments will require more specific identifications. 


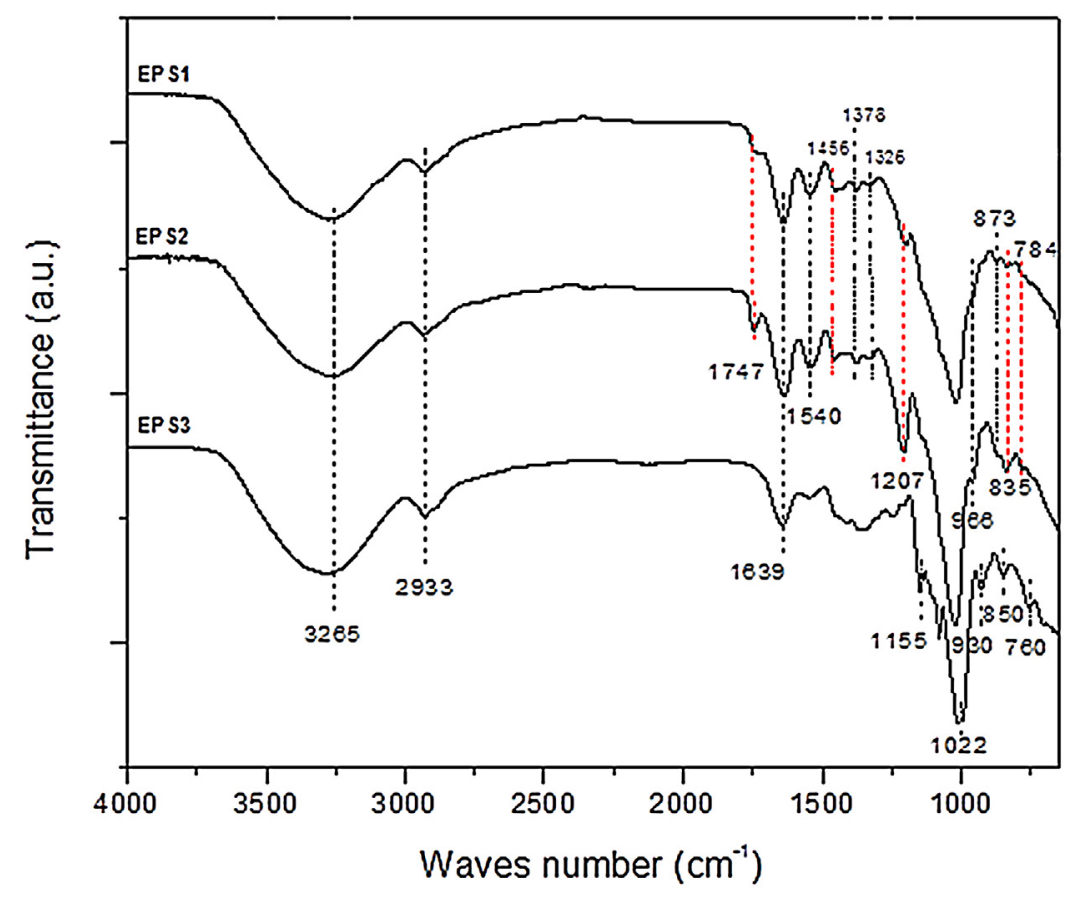

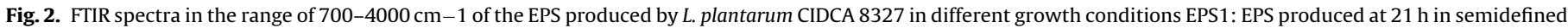
medium(SDM); EPS2: EPS produced at $96 \mathrm{~h}$ in SDM; and EPS3: EPS produced after $96 \mathrm{~h}$ in milk.

The intensities of the resonances contain information about the branched structure of the molecule. In this case, the ratio of the integrated peaks of $\mathrm{H} 1-4, \mathrm{H} 1-3, \mathrm{H} 1-6$ and $\mathrm{H} 4^{\prime}$ is 47:12:0.38:1.

Gathering all data collected for EPS 3, this polysaccharide can be described as a branched $\alpha-(1 \rightarrow 4)$-D-glucan with a molecular mass of around $9000 \mathrm{Da}$, composed of $80 \%$ linear $\alpha-(1 \rightarrow 4)$ D-glucopyranosyl units and 19\% ( $1 \rightarrow 4)$-D-glucopyranosyl units substituted at $O-3$ by single $\alpha$-D-glucopyranosil residues or $\alpha$ $(1 \rightarrow 4)$ disaccharidic side chains (Fig. 4A and B).

\section{Discussion}

The functional aspects of fermented foods are mostly related to the concept of probiotic bacteria however the microbial production of functional molecules, such as bioactive EPS, is targeted (Leroy \& De Vuyst, 2016). Kefir grains are an interesting source of EPSproducing bacteria (Hamet et al., 2015; Moura de Paiva et al., 2016). Herein we demonstrated that L. plantarum CIDCA 8327 isolated from kefir is able to produce EPS in milk or SDM, whose composition depends on the growth conditions. Otherwise, this is the first report of the production of $\alpha$-glucan by a strain of $L$. plantarum isolated from kefir after growth in milk. Accordingly, by amplification and sequencing of a PCR fragment with a high degree of homology with the cps 3 cluster of $L$. plantarum WCSF1, we are proving the presence of genes involved in the CPS/EPS polysaccharide synthesis in the genome of $L$. plantarum CIDCA 8327.

It is noteworthy that $L$. plantarum CIDCA 8327 EPS remains in part loosely bound to the surface of the bacteria and may be involved in the interactions with their environment playing an important role in the communication between bacteria and the host organisms (Abraham, Medrano, Piermaria, \& Mozzi, 2010; Chap. 10). Therefore, improved knowledge on these molecules is of great importance to understand the strain-specific and proposed beneficial modes of probiotic action (Remus et al., 2012).

The EPS produced by L. plantarum CIDCA 8327 in SDM was a heteropolysaccharide composed mainly of glucose, glucosamine and rhamnose. Harvesting the EPS at two incubation times allowed observing that the molecular mass of the EPS recovered was higher upon a longer period, but without relevant changes in monosaccharide composition, suggesting that polymerization continues even in the stationary growth phase. Analysis of previous reports about characterization of EPS produced by different strains of $L$. plantarum, allows concluding that most of the strains produce heteropolysaccharides when grown in media containing glucose or lactose as the carbon source (Ismail \& Nampoothiri, 2010; Remus et al., 2012; Tallon et al., 2003; Wang et al., 2010; Zhou et al., 2016). On the contrary, L. plantarum 70810 grown in a SD with lactose as unique carbon source produce a galactan (Wang et al., 2014).

Biosynthesis of CPS/EPS inside the cell occurs by activation of the precursor molecules by enzymes producing activated sugars/sugar acids by three possible mechanisms: the Wzx/Wzy-dependent pathway, the synthase-dependent pathway and the ATP binding cassette $(A B C)$ transporter-dependent pathway. Alternatively, the extracellular synthesis by use of a single sucrase protein is used for the polymer strand elongation (Schmid, Sieber, \& Rehm, 2015). Studies of the L. plantarum WCFS1 genome demonstrates that 4 gene clusters (designated cps genes), associated in two regions, independently contribute to the overall surface-associated polysaccharide. The first region has three cps gene clusters (1-3), and the second region comprises the cps 4 gene cluster and is conserved in other L. plantarum strains (ST-III, ATCC14917). In L. plantarum WCFS1, the polymerase genes implicated in the polymerization of the polysaccharide repeating units were found in the $4 \mathrm{cps}$ clusters (Remus et al., 2012). DNA of L. plantarum CIDCA 8327 was amplified with the $c p s 3 E-F$ primers giving only one PCR product. At the 1112418 base position of the genome of WCFS1 strain, a guanine breaks the reading frame of the $c p s 3 F$ gene, but this not is the case in L. plantarum CIDCA 8327, like other strains sequenced (L. plantarum subsp. plantarum ST-III, Accession Number CP002222.1 or $L$. plantarum ZJ316, Accesion Number CP004082.1).

In L. plantarum WCFS1, Remus et al. (2012) reported that it was unclear if a functional Wzy protein can be composed of Cps3F and CpsG. In L. plantarum CIDCA 8327, no putative conserved domains were detected, although the predicted amino acid sequence of the 


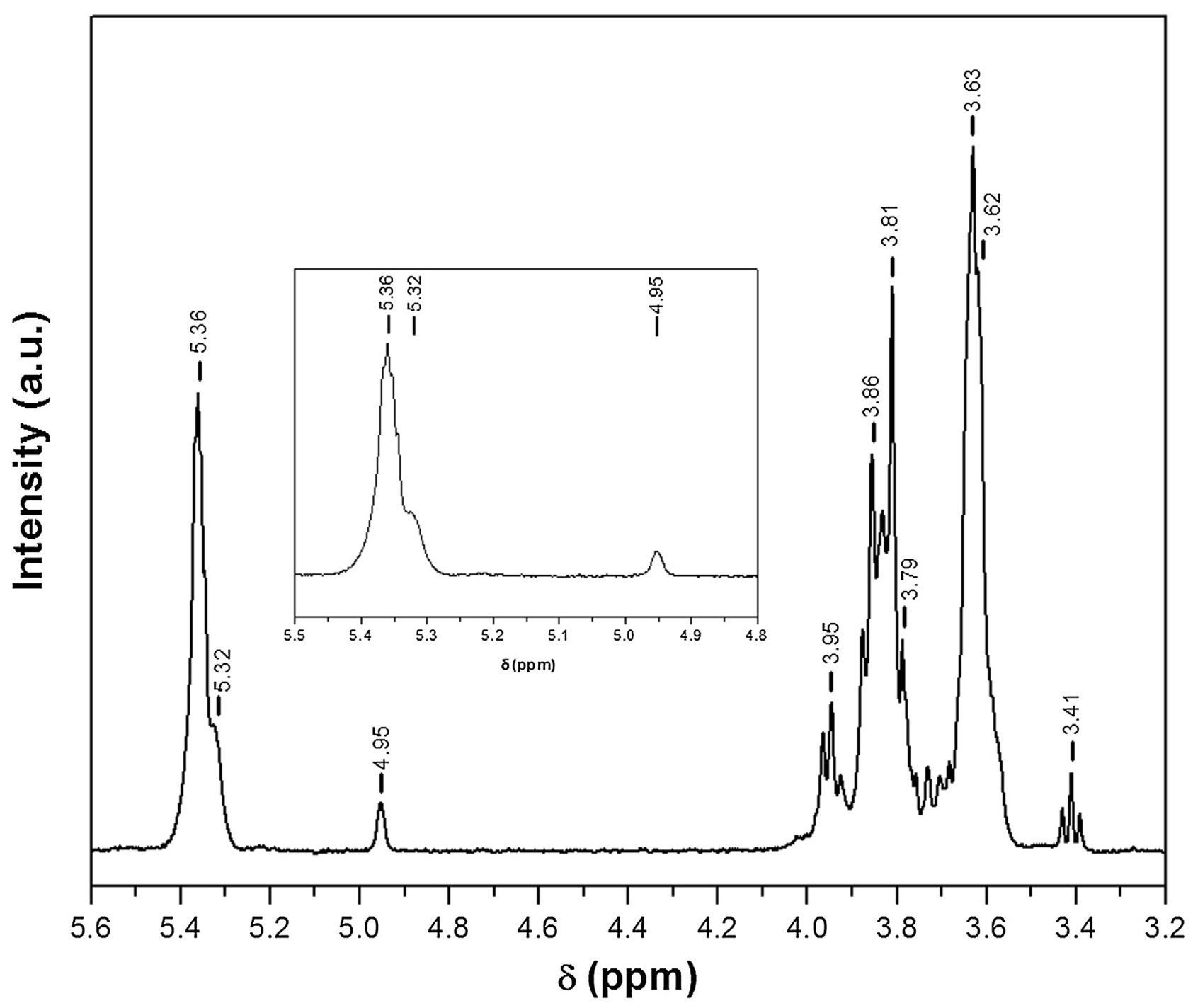

Fig. 3. ${ }^{1} \mathrm{H}$ NMR spectra of EPS produced by L. plantarum CIDCA 8327 in milk (EPS3).
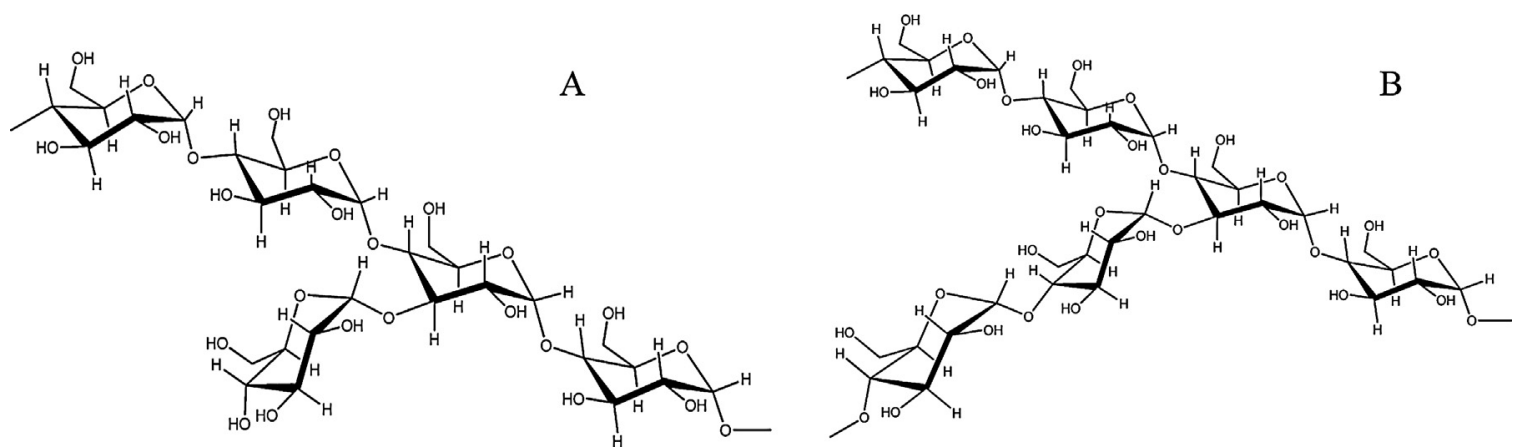

Fig. 4. Suggested structures for EPS produced by L. plantarum CIDCA 8327 in milk. Linear $\alpha$-( $1 \rightarrow 4$ )-D-glucopyranosyl units and $(1 \rightarrow 4)$-D-glucopyranosyl units substituted at $O-3$ by single $\alpha$-D-glucopyranosil residues (A) or $\alpha-(1 \rightarrow 4)$ disaccharidic side chains (B).

PCR fragment presented high identity with polysaccharide polymerase Wzy proteins like $L$. rhamnosus GG strain that produces a galactose-rich EPS (Lebeer et al., 2009).

When grown in milk, L. plantarum CIDCA 8327 produces a homopolysaccharide of around $10^{4}$ Da composed only of glucose. The milk fermented with this strain presented a pseudoplastic behavior with a hysteresis loop that did not differ from the flow curve of an acid gel obtained with D-gluconolactone (Hamet et al., 2015) in concordance to the expected behavior of an EPS with low molecular mass distribution. The FTIR spectrum of the EPS produced in milk showed typical polysaccharide signals, and all the vibrational peaks were similar to those obtained for $\alpha$-glucans. Enzymes involved in $\alpha$-glucans synthesis are glucansucrases that catalyze the polymerization of the homopolysaccharide out of 
sucrose as donor of the corresponding monosaccharide, and transfer the molecule to the reducing end of the glucan (Leemhuis et al., 2013). L. plantarum CIDCA 8327 synthetize $\alpha$ - glucan from lactose, in consequence the existence of another pathway involved could not be ruled out. According to the main glycosidic linkages, $\alpha$-glucans are classified into dextrans $(\alpha-1,6)$, mutans $(\alpha-1,3)$, reuterans $(\alpha-1,4)$ and alternans $(\alpha-1,3$ and $\alpha-1,6)$ (Leemhuis et al., 2013). Both ${ }^{1} \mathrm{H}$ NMR and methylation analysis allowed to determine that this polysaccharide consists of a $\alpha-(1 \rightarrow 4)$-D-glucan with $19 \%$ branching at positions $O-3$. Side chains could be made up of a single $\alpha$-D-glucopyranosil unit or of a $\alpha$-(1 $\rightarrow 4)$-glucopyranose disaccharide.

Dextran-producer lactic acid bacteria belong to the genera Lactobacillus, Pediococcus, Leuconostoc and Weissella (Torino, de Valdez, \& Mozzi, 2015). Focusing on Lactobacillus isolated from sugary kefir, Moura de Paiva et al. (2016) demonstrated that L. kefiranofaciens $1 \mathrm{P} 3$ and $L$. satsumensis $10 \mathrm{P}$ and 10P2 grown in the presence of sucrose produced an $\alpha$-glucan linked by $\alpha-(1,6)$ glycosidic bonds ( 90\%).

Production of $\alpha$-glucans by L. plantarum strains was reported by Das and Goyal (2013). When grown in medium with sucrose, L. plantarum DM5 produces an $\alpha$-glucan that contains $86.5 \% \alpha$ $(1 \rightarrow 6)$ linear linkages, with $13.5 \% \alpha-(1 \rightarrow 3)$ branched linkages. $L$. plantarum CIDCA 8327 produces an $\alpha$-glucan with $\alpha-(1 \rightarrow 4)$ glycosidic linkages similar to reuteran, but in this case the main chain is branched at positions $0-3$ and not in $0-6$, which distinguishes the EPS described here from other $\alpha-(1 \rightarrow 4)$-glucans. To the best of our knowledge, this is the first report of a polysaccharide from LAB with this structure. Up to the moment, strains of $L$. reuteri were described as reuteran producers (Patel, Majumder, \& Goyal, 2012; Tieking \& Gänzle, 2005). It is noteworthy that L. plantarum CIDCA 8327 produces $\alpha$-glucan after growth in milk and this fact may contribute to the probiotic properties of this strain.

Among $\alpha$-glucans, dextran and dextran-derived oligosaccharides have been reported to elicit some prebiotic effect in vitro (Das et al., 2014; Rao \& Goyal, 2013). Sarbini, Kolida, Deaville, Gibson, and Rastall (2014) correlated this effect on intestinal microbiota elicited by dextran with obesity management. Recently, two dextrans synthesized by L. sakei MN1 and L. mesenteroides RTF10 demonstrated to have antiviral and immunomodulatory activity against salmonid viruses (Nácher-Vázquez et al., 2015).Otherwise, it was described that $\alpha-(1 \rightarrow 4)$ glucans have a role in the induction of phagocytosis (Bittencourt et al., 2006; Nair, Melnick, Ramachandran, Escalon, \& Ramachandran, 2006), nevertheless the ability to escape digestion of each EPS should be demonstrated.

It can be concluded that L. plantarum CIDCA 8327 isolated from kefir grain produces EPS with different sugar composition depending on the growth medium. In a SDM with glucose as the carbon source, several monosaccharides are released upon acid hydrolysis of the obtained polymer, suggesting the presence of heteropolysacharides, while when grown in milk an extracellular $\alpha$-glucan was synthetized. The EPS remains loosely bond to the bacterial cell. Taking into account that these strains associate to epithelial cells in vitro and exert a protective in vitro effect against Salmonella invasion (Golowczyc et al., 2008; Londero et al., 2012) the presence of this EPS could be a relevant factor in health promoting properties. This is the first report of an $\alpha$-glucan producer strain isolated from kefir after growth in milk. Further studies to provide additional information on the structure of the glucan (periodate oxidation, Smith-degradation of oxidized products, more detailed NMR characterization) will be performed in future work. Our results encourage further investigations about the role of $\alpha$-glucans produced by L. plantarum CIDCA 8327 that could contribute to comprehend the potential probiotic properties of this strain.

\section{Acknowledgments}

MVG is a member of the Researcher Career of CICPBA. PP, MM and AGA are members of Scientific Career of CONICET. AIP and MTD are supported by Universidad del Pais Vasco. AP is researcher from CSIC.

This study was supported by grants from the Agencia Nacional de Promoción Científica y Tecnológica (ANPCyT), CONICET and UNLP, the Spanish Ministry of Science and Innovation (AGL201240084-C03), the Basque Government (no. IT866-13). M.G.Ll. acknowledges the 'Gobierno Vasco, Dpto. Agricultura, Pesca y Alimentación' for the fellowship. We also thank Microscopy: Polymer Characterization Service (SGIker) from the University of the Basque Country.

\section{References}

Abraham, A. G., Medrano, M., Piermaria, J. A., \& Mozzi, F. (2010). Novel applications of polysaccharides from lactic acid bacteria: A focus on kefiran (Review article). In C. S. Hollingworth (Ed.), Food hydrocolloids: Characteristics, properties and structures (pp. 253-271). New York: Nova Publishers, Inc.

Bittencourt, V. C. B., Figueiredo, R. T., da Silva, R. B., Mourão-Sá, D. S., Fernandez, P. L., Sassaki, G. L., et al. (2006). An $\alpha$-glucan of Pseudallescheria boydii is involved in fungal phagocytosis and Toll-like receptor activation. Journal of Biological Chemistry, 281, 22614-22623

Bremer, P. J., \& Geesey, G. G. (1991). An evaluation of biofilm development utilizing non-destructive attenuated total reflectance Fourier transform infrared spectroscopy. Biofouling, 3, 89-100.

Cheng, H. N., \& Neiss, T. G. (2012). Solution NMR spectroscopy of food polysaccharides. Polymer Reviews, 52, 81-114.

Ciucanu, I., \& Kerek, F. (1984). Rapid and simultaneous methylation of fatty and hydroxy fatty acids for gas-liquid chromatographic analysis. Journal of Chromatography A, 284, 179-185.

Das, D., \& Goyal, A. (2013). Characterization and biocompatibility of glucan: A safe food additive from probiotic Lactobacillus plantarum DM5. Journal of the Science of Food and Agriculture, 94, 683-690.

Das, D., Baruah, R., \& Goyal, A. (2014). A food additive with prebiotic properties of an $\alpha$-D-glucan from Lactobacillus plantarum DM5. International Journal of Biological Macromolecules, 69, 20-26.

De Man, J. C., Rogosa, D., \& Sharpe, M. E. (1960). A medium for the cultivation of lactobacilli. Journal of Applied Bacteriology, 23, 130-135.

Dilna, S. V., Surya, H., Aswathy, R. G., Varsha, K. K., Sakthikumar, D. N., Pandey, A. et al. (2015). Characterization of an exopolysaccharide with potential health-benefit properties from a probiotic Lactobacillus plantarum RJF 4. LWT-Food Science and Technology, 64, 1179-1186.

Garrote, G. L., Abraham, A. G., \& De Antoni, G. L. (2001). Chemical and microbiological characterisation of kefir grains. Journal of Dairy Research, 68, 639-652.

Golowczyc, M. A., Gugliada, M. J., Hollmann, A. J., Delfederico, L., Garrote, G. L., Abraham, A. G., et al. (2008). Characterization of homofermentative lactobacilli isolated from kefir grains: Potential use as probiotic. Journal of Dairy Research, 75, 211-217.

Hamet, M. F., Piermaria, J. A., \& Abraham, A. G. (2015). Selection of EPS-producing Lactobacillus strains isolated from kefir grains and rheological characterization of the fermented milks. LWT-Food Science and Technology, 63, 129-135.

Hamet, M. F., Medrano, M., Pérez, P. F., \& Abraham, A. G. (2016). Oral administration of kefiran exerts a bifidogenic effect on Balb/c mice intestinal microbiota. Beneficial Microbes, 7, 237-246.

Hidalgo-Cantabrana, C., Patricia López, P., Gueimonde, M., de los Reyes-Gavilán, C. G., Suárez, A., Margolles, A., et al. (2012). Immune modulation capability of exopolysaccharides synthesised by lactic acid bacteria and bifidobacteria. Probiotics and Antimicrobial Proteins, 4, 227-237.

Howe, K. J., Ishida, K. P., \& Clark, M. M. (2002). Use of ATR/FT-IR spectrometry to study fouling of microfiltration membranes by natural waters. Desalination, $147,251-255$.

Ibarburu, I., Puertas, A. I., Berregi, I., Rodríguez-Carvajal, M. A., Prieto, A., \& Dueñas, M. T. (2015). Production and partial characterization of exopolysaccharides produced by two Lactobacillus suebicus strains isolated from cider. International Journal of Food Microbiology, 214, 54-62.

Ismail, B., \& Nampoothiri, K. M. (2010). Production, purification and structural characterization of an exopolysaccharide produced by a probiotic Lactobacillus plantarum MTCC 9510. Archives of Microbiology, 192, 1049-1057.

Kačuráková, M., Capek, P., Sasinkova, V., Wellner, N., \& Ebringerova, A. (2000). FT-IR study of plant cell wall model compounds: Pectic polysaccharides and hemicelluloses. Carbohydrate Polymers, 43, 195-203.

Korakli, M., Gänzle, M. G., \& Vogel, R. F. (2002). Metabolism by bifidobacteria and lactic acid bacteria of polysaccharides from wheat and rye, and exopolysaccharides produced by Lactobacillus sanfranciscensis. Journal of Applied Microbiology, 92, 958-965. 
Kovács, A., Nyerges, B., \& Izvekov, V. (2008). Vibrational analysis of $\mathrm{N}$-acetyl- $\alpha$-D-glucosamine and $\beta$-D-glucuronic acid. Journal Physics of Chemistry, 112, 5728-5735.

Laine, R., Sweeley, C. C., Li, Y. T., Kisic, A., \& Rapport, M. M. (1972). On the structure of cytolipin R, a ceramide tetrahexoside hapten from rat lymphosarcoma. Journal of Lipid Research, 13, 519-524.

Lebeer, S., Verhoeven, T. L., Francius, G., Schoofs, G., Lambrichts, I., Dufrêne, Y., et al. (2009). Identification of a gene cluster for the biosynthesis of a long, galactose-rich exopolysaccharide in Lactobacillus rhamnosus GG and functiona analysis of the priming glycosyltransferase. Applied and Environmental Microbiology, 75, 3554-3563.

Leemhuis, H., Pijning, T., Dobruchowska, J. M., van Leeuwen, S. S., Kralj, S., Dijkstra B. W., et al. (2013). Glucansucrases: Three-dimensional structures, reactions, mechanism, $\alpha$-glucan analysis and their implications in biotechnology and food applications. Journal of Biotechnology, 163, 250-272.

Leroy, F., \& De Vuyst, L. (2016). Advances in production and simplified methods for recovery and quantification of exopolysaccharides for applications in food and health. Journal of Dairy Science, 99, 3229-3238.

Londero, A., Quinta, R., Abraham, A. G., Sereno, R., De Antoni, G., \& Garrote, G. L. (2011). Inhibitory activity of cheese whey fermented with kefir grains. Journal of Food Protection, 1, 94-100.

Marieta, C., Ibarburu, I., Dueñas, M., \& Irastorza, A. (2009). Supramolecular structure and conformation of a $(1 \rightarrow 3)(1 \rightarrow 2)-\beta$-D-glucan from Lactobacillus suebicus CUPV221 as observed by tapping mode atomic force microscopy. Journal of Agricultural and Food Chemistry, 57, 6183-6188.

Medrano, M., Hamet, M. F., Abraham, A. G., \& Pérez, P. F. (2009). Kefiran protects Caco-2 cells from cytopathic effects induced by Bacillus cereus infection. Antonie Van Leeuwenhoek, 96, 505-513.

Medrano, M., Racedo, S. M., Rolny, I. S., Abraham, A. G., \& Pérez, P. F. (2011). Oral administration of kefiran modulates the immune cell balance of lymphoid tissues associated to intestinal mucosa. Journal of Agricultural and Food Chemistry, 59, 5299-5304.

Moura de Paiva, I., da Silva Steinberg, R., Lula, I. S., de Souza-Fagundes, E. M., de Oliveira Mendes, T., Bell, M. J. V., et al. (2016). Lactobacillus kefiranofaciens and Lactobacillus satsumensis isolated from Brazilian kefir grains produce alpha-glucans that are potentially suitable for food applications. LWT-Food Science and Technology, 72, 390-398.

Mozzi, F., Vaningelgem, F., Hébert, E. M., Van der Meulen, R., Moreno, M. R. F., de Valdez, G. F., et al. (2006). Diversity of heteropolysaccharide-producing lactic acid bacterium strains and their biopolymers. Applied and Environmental Microbiology, 72, 4431-4435.

Nácher-Vázquez, M., Ballesteros, N., Canales, A., Rodríguez Saint-Jean, S. Pérez-Prieto, S. I., Prieto, A., et al. (2015). Dextrans produced by lactic acid bacteria exhibit antiviral and immunomodulatory activity against salmonid viruses. Carbohydrate Polymers, 124, 292-301.

Nair, P. R., Melnick, S. J., Ramachandran, R., Escalon, E., \& Ramachandran, C. (2006) Mechanism of macrophage activation by $(1,4)-\alpha$-D-glucan isolated from Tinospora cordifolia. International Immunopharmacology, 6, 1815-1824

Nataraj, S., Schomacker, R., Kraume, M., Mishra, M. I., \& Drews, A. (2008). Analyse of polysaccharide fouling mechanisms during crossflow membrane filtration. Journal of the Membrane Science, 308, 152-161.

Nilsson, G. S., Bergquist, K. E., Nilsson, U., \& Gorton, L. (1996). Determination of the degree of branching in Normal and amylopectin type potato starch with ${ }^{1} \mathrm{H}$ NMR spectroscopy. Improved resolution and two-dimensional spectroscopy. Starch, 48, 352-357.

Notararigo, N., Nácher-Vázquez, M., Ibarburu, I., Werning, M. L., Fernández de Palencia, P., Dueñas, M. T., et al. (2013). Comparative analysis of production and purification of homo- and hetero-polysaccharides produced by lactic acid bacteria. Carbohydrate Polymers, 93, 57-64.
Patel, S., Majumder, A., \& Goyal, A. (2012). Potentials of exopolysaccharides from lactic acid bacteria. Indian Journal of Microbiology, 52, 3-12.

Patten, D. A., \& Laws, A. P. (2015). Lactobacillus-produced exopolysaccharides and their potential health benefits: A review. Beneficial Microbes, 6, 1-15.

Rao, J. M., \& Goyal, A. (2013). A novel high dextran yieldin Weissella cibaria JAG8 for cereal food application. International Journal of Food Science E Nutrition, 64, 346-354.

Remus, D. M., van Kranenburg, R., van Swam, I. I., Taverne, N., Bongers, R. S., Wels M., et al. (2012). Impact of 4 Lactobacillus plantarum capsular polysaccharide clusters on surface glyca composition and host cell signaling. Microbial Cell Factories, 11, 149.

Rimada, P., \& Abraham, A. G. (2003). Comparative study of different methodologies to determine the exopolysaccharide produced by kefir grains in milk and whey. Le Lait, 83, 79-88.

Sarbini, S. R., Kolida, S., Deaville, E. R., Gibson, G. R., \& Rastall, R. A. (2014). Potential of novel dextran oligosaccharides as prebiotics for obesity management through in vitro experimentation. British Journal of Nutrition, 112, 1303-1314.

Schmid, J., Sieber, V., \& Rehm, B. (2015). Bacterial exopolysaccharides: biosynthesis pathways and engineering strategies. Frontiers in Microbiology, 6, 496.

Synytsya, A., \& Novak, M. (2014). Structural analysis of glucans. Annals Translation Medicine, 2, 17.

Tallon, R., Bressollier, P., \& Urdaci, M. C. (2003). Isolation and characterization of two exopolysaccharides produced by Lactobacillus plantarum EP56. Research in Microbiology, 154, 705-712.

Tieking, M., \& Gänzle, M. G. (2005). Exopolysaccharides from cereal-associated lactobacilli. Trends in Food Science \& Technology, 16, 79-84.

Torino, M. I., de Valdez, G. F., \& Mozzi, F. (2015). Biopolymers from lactic acid bacteria. Novel applications in foods and beverages. Frontiers in Microbiology, 6.

Wang, K., Li, W., Liu, P., Ahmed, Z., Xiao, P., \& Bai, X. (2010). Physical characterization of exopolysaccharide produced by Lactobacillus plantarum KF5 isolated from Tibet Kefir. Carbohydrate Polymers, 82, 895-903.

Wang, K., Li, W., Rui, X., Chen, X., Jiang, M., \& Dong, M. (2014). Characterization of a novel exopolysaccharide with antitumor activity from Lactobacillus plantarum 70810. International Journal of Biological Macromolecules, 63, 133-139.

Wang, J., Zhao, X., Tian, Z., Yang, Y., \& Yang, Z. (2015). Characterization of an exopolysaccharide produced by Lactobacillus plantarum YW11 isolated from Tibet Kefir. Carbohydrate Polymers, 125, 16-25.

Zang, L.-H., Rothman, D. L., \& Shulman, R. G. (1990). ${ }^{1} \mathrm{H}$ NMR visibility of mammalian glycogen in solution. Biophysics, 87, 1678-1680.

Zang, L.-H., Howseman, A. M., \& Shulman, R. G. (1991). Assignment of the $1 \mathrm{H}$ chemical shifts of glycogen. Carbohydrate Research, 220, 1-9.

Zhang, L., Liu, C., Li, D., Zhao, Y., Zhang, X., Zeng, X., et al. (2013). Antioxidant activity of an exopolysaccharide isolated from Lactobacillus plantarum C88. International Journal of Biological Macromolecules, 54, 270-275.

Zhang, L., Liu, C., Tao, X., \& Wei, H. (2016). Characterization and sulfated modification of an exopolysaccharide from Lactobacillus plantarum ZDY2013 and its biological activities. Carbohydrate Polymers, 153, 25-33.

Zhou, K., Zeng, Y., Yang, M., Chen, S., He, L., Ao, X., et al. (2016). Production: purification and structural study of an exopolysaccharide from Lactobacillus plantarum BC-25. Carbohydrate Polymers, 144, 205-214.

Živković, M., Miljković, M. S., Ruas-Madiedo, P., Markelić, M. B., Veljović, K., Tolinački, M., et al. (2016). EPS-SJ exopolysaccharide produced by the strain Lactobacillus paracasei subsp. paracasei BGSJ2-8 is involved in adhesion to epithelial intestinal cells and decrease on E. coli association to Caco-2 cells. Frontiers in Microbiology, 7, 286. 